\title{
PSEUDO CENTRAL CERVICAL FIBROID IN A NULLIPAROUS GIRL: A CASE REPORT
}

Priyankur Roy ${ }^{1}$, Bivas Biswas ${ }^{2}$, Santosh Thomas ${ }^{3}$, Anumita Chatterjee ${ }^{4}$, Ruby Jose ${ }^{5}$

\section{HOW TO CITE THIS ARTICLE:}

Priyankur Roy, Bivas Biswas, Santosh Thomas, Anumita Chatterjee, Ruby Jose. "Pseudo Central Cervical Fibroid in a Nulliparous Girl: A Case Report". Journal of Evolution of Medical and Dental Sciences 2014; Vol. 3, Issue 39, August 28; Page: 9889-9891, DOI: 10.14260/jemds/2014/3280

ABSTRACT: Fibroids are benign (non-cancerous) growths on the uterus. There is an overall incidence of $20 \%$ in women more than $30 y$ rs of age. The incidence of cervical fibroids is much lower at $1-2 \%$. An unmarried girl presented with complaints of difficulty in passing urine, lower abdominal pain and spasmodic dysmenorrhea for 4 months. Per abdomen there was a firm, non-tender midline mass arising from the pelvis corresponding to 20 weeks size gravid uterus with restricted mobility. Cervix could not be felt. Ultrasonographic examination showed $10.2 \times 10.7 \mathrm{~cm}$ fibroid in the posterior wall with no adnexal pathology and bilateral mild hydronephrosis. On laparotomy, the uterus was found to be sitting like a lantern on the dome of St. Paul's Cathedral. A $25 \times 18 \mathrm{~cm}$ pseudo central cervical fibroid, partly intramural, partly sub mucous was seen to arise from the posterior cervico isthmic region. Myomectomy was performed successfully. Central cervical fibroid expands the cervix equally in all directions and the uterus is elevated on top of the large tumor. Diagnosis is by ultrasonogram and HSG. Management in cervical fibroid of supravaginal portion is hysterectomy if fertility is not desired and myomectomy if the patient is young and fertility is desired, as in our case.

KEYWORDS: Pseudo Central Cervical Fibroid, Myomectomy.

INTRODUCTION: Fibroids are benign (non-cancerous) growths on the uterus. There is an overall incidence of $20 \%$ in women more than $30 y$ rs of age. The incidence of cervical fibroids is much lower at $1-2 \%{ }^{1}$. They arise either from the portio vaginalis presenting as a fibroid polyp or from the supravaginal cervix presenting either as an interstitial, subserous or submucous fibroid.

CASE HISTORY: A 21 year old, unmarried girl presented to Christian Medical College and Hospital, Vellore with complaints of difficulty in passing urine, lower abdominal pain and spasmodic dysmenorrhea for 4 months. She was evaluated at her hometown and told to have a $15 \times 10 \mathrm{~cm}$ subserosal fibroid. Systemic examination was normal.

Per abdomen there was a firm, non-tender midline mass arising from the pelvis corresponding to 20 weeks size gravid uterus with restricted mobility. Per vaginal examination with consent was done and a polypoidal mass measuring $10 \times 8 \mathrm{~cm}$ was found filling the entire vagina. Cervix could not be felt. Ultrasonographic examination showed $10.2 \times 10.7 \mathrm{~cm}$ fibroid in the posterior wall with no adnexal pathology and bilateral mild hydronephrosis.

She was planned for examination under anesthesia and laparotomy with consent taken for hysterectomy, if required at CMC and Hospital, Vellore. Blood was available if necessary. Intraoperatively, a huge fibroid polyp was seen vaginally. It was not possible to get above the swelling, the cervix could not be felt and the tumor did not have any plane to enucleate and thus it was decided to proceed to laparotomy. On laparotomy, both tubes and ovaries were normal. The uterus was sitting like a lantern on the dome of St. Paul's Cathedral. 
A 25 X18 cm pseudo central cervical fibroid, partly intramural, partly sub mucous was seen to arise from the posterior cervico isthmic region. Bonney's rubber shod clamps were applied along the uterine vessels and a myomectomy was performed. There were no other fibroids felt and the cervix was felt to be normal at the end of the laparotomy. Since the cavity was entered into, she was advised low dose combined oral contraceptive pills for 3 cycles and to have elective LSCS during pregnancy. At the follow up visit 4 months post operatively she was found to be doing well.

DISCUSSION: Cervical fibroids are classified as true and false. True cervical fibroids are further subdivided into anterior, posterior, lateral, central and multiple. False cervical fibroids are classified into intra-ligamentary, retroperitoneal, non-capsulated ${ }^{2}$. The size, growth, number and progression of cervical fibroids are unpredictable and rarely do they become cancerous (less than $0.1 \%$ ). ${ }^{3}$ They are unlikely to shrink or disappear on their own until after menopause.

Those arising from portio vaginalis usually present as cervical fibroid polyp and are easily felt as mass protruding from the cervix. ${ }^{4}$ Central tumor expands the cervix equally in all directions and the uterus is elevated on top of the large tumor. Diagnosis is by ultrasonogram and HSG. ${ }^{5}$

Management in cervical fibroid of supravaginal portion is hysterectomy if fertility is not desired and myomectomy if the patient is young and fertility is desired. ${ }^{6}$

CONCLUSION: Fertility factor should always be kept in the mind before proceeding with surgery for such cases. But, the treatment of choice in a case of parous woman with completed family is always hysterectomy.

In a nulliparous woman, an extensive pre-operative workup, exclusion of a concurrent adnexal disease, informed consent for probable hysterectomy, anticipation of blood loss and operative challenges are to be considered when faced with a cervical fibroid.

\section{REFERENCES:}

1. Myomectomy and the Management of Fibroids in Pregnancy, Bonney's Gynecological Surgery (Tenth Edition), Pgs 87-94.

2. Rein MS, Barbieri RL, Friedman AJ. Progesterone: A critical role in the pathogenesis of uterine myomas. Am J Obstet Gynaecol 1995; 172: 14.

3. Dicker RC, Greenspan JR, Strauss LT, et al. Complications of abdominal and vaginal hysterectomy among women of reproductive age in the United States. Am J Obstet Gynecol 1982; 144: 841-848.

4. Thompson JD, Warshaw JS. Hysterectomy Rock JA, Thompson JD. Telinde's Operative Gynecology 8th edition 1997 Philadelphia: Lippincott-Raven.

5. John D Thompson, John A Rock. Leiomyomata uteri and myomectomy, in TeLinde's textbook of operative gynecology 9 th edition.

6. Dorsey JH, Steinberg EP, Holtz PM. Clinical indications for hysterectomy route: patient characteristics or physician preference? Am J Obstet Gynecol 1995; 173: 1452-1460. 


\section{CASE REPORT}

\section{PHOTOGRAPH SHEET}

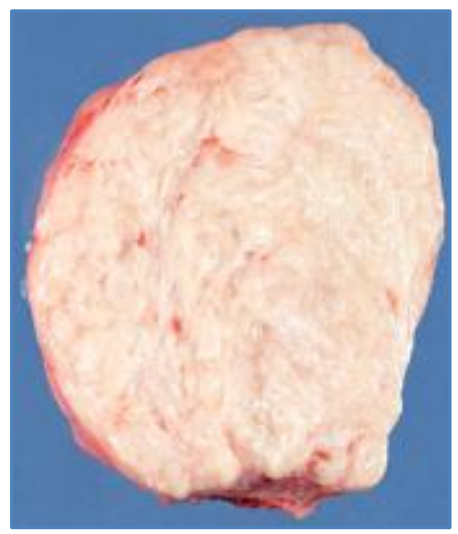

Picture 1: Cut-section of the Fibroid after Myomectomy

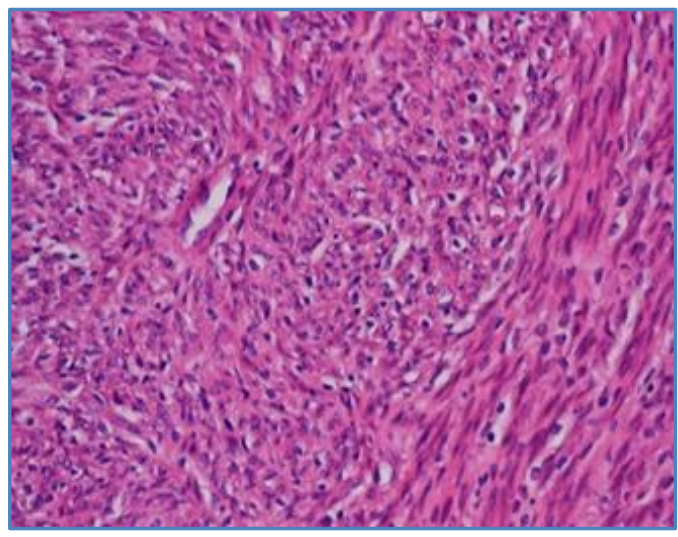

Picture 2: Histopathological Examination, H \& E stain: Leiomyoma

\section{AUTHORS:}

1. Priyankur Roy

2. Bivas Biswas

3. Santosh Thomas

4. Anumita Chatterjee

5. Ruby Jose

\section{PARTICULARS OF CONTRIBUTORS:}

1. Post Graduate Registrar, Department of Obstetrics and Gynaecology, JSS Medical College. Mysore. India.

2. Senior Clinical Fellow, Department of Obstetrics and Gynaecology, King's Mill Hospital, Nottinghamshire, UK.

3. Consultant, Department of Obstetrics and Gynaecology, Nalam Hospital, Vellore, India.

4. Intern, Department of Obstetrics and Gynaecology, JSS Medical College. Mysore. India.
5. Professor and Head of Unit IV, Department of Obstetrics and Gynaecology, Christian Medical College, Vellore, India.

\section{NAME ADDRESS EMAIL ID OF THE CORRESPONDING AUTHOR:}

Dr. Priyankur Roy,

Department of Obstetrics and Gynaecology,

JSS Medical College,

Mysore.

Email: priyankurroy@gmail.com

Date of Submission: 20/08/2014.

Date of Peer Review: 21/08/2014.

Date of Acceptance: 25/08/2014.

Date of Publishing: 27/08/2014. 